\title{
Pengaruh Shopping Lifestyle Dan Fashion Involvement Terhadap Impulse Buying Pada Konsumen Hijab Butik Rabbani Jombang
}

\author{
Shintia Fitri Febriani, Nuri Purwanto \\ STIE PGRI Dewantara Jombang
}

Korespondensi : nuri.stiedw@gmail.com

\begin{abstract}
abstrak
Penelitian ini bertujuan untuk mengetahui pengaruh gaya hidup belanja dan keterlibatan fashion terhadap pembelian impulsif konsumen hijab butik Rabbani Jombang. Jenis penelitian ini adalah jenis penelitian korelasional, dengan menggunakan pendekatan kuantitatif . Populasi dalam penelitian ini adalah semua konsumen yang belum pernah membeli jilbab di butik Rabbani sedangkan sampel dalam penelitian ini adalah 100 orang yang diambil dengan menggunakan teknik Accidental sampling. Teknik pengumpulan data menggunakan kuesioner. Metode analisis data dalam penelitian ini menggunakan analisis regresi linier berganda dengan alat statistik SPSS 20. Hasil penelitian menunjukkan bahwa gaya hidup belanja dan keterlibatan mode secara signifikan mempengaruhi pembelian impulsif.

Kata kunci: Gaya Hidup Berbelanja, Keterlibatan Fashion, Pembelian Impulsif

\section{abstract}

This study aims to determine the influence of shopping lifestyle and fashion involvement on impulsive purchases of Rabbani Jombang boutique hijab consumers. This type of research is a type of correlational research, using a quantitative approach. The population in this study were all consumers who had never bought a headscarf in Rabbani boutique while the sample in this study were 100 people taken using Accidental sampling technique. The technique of collecting data using a questionnaire. The method of data analysis in this study used multiple linear regression analysis with SPSS 20 statistical tools.

The results showed that shopping lifestyle and fashion involvement significantly affected impulsive purchases.
\end{abstract}

Keywords: Shopping Lifestyle, Fashion Engagement, Impulsive buying

\section{A. PENDAHULUAN}

Dewasa ini berbelanja merupakan kegiatan yang sulit dilepaskan dari manusia, baik laki-laki maupun wanita, walaupun terkadang berbelanja lebih banyak dilakukan oleh wanita, mulai dari berbelanja kebutuhan hidup, belanja kebutuhan pribadi dan lain-lain, termasuk salah satunya berbelanja produk fashion terlebih lagi dengan dukungan perkembangan internet yang semakin memancing minat beli, memudahkan konsumen untuk memilih serta melakukan pembelian secara online (Arisandi, D., \& Pradana, M. N. R, 2018). Apalagi jika produk tersebut direkomendasikan oleh teman dekat melalui iklan dari mulut ke mulut yang lebih dikenal dengan istilah word of mouth (Rohim, A., \& Arvianto, S, 2017). Fashion selalu mengalami perubahan setiap tahunnya. Aspek-aspek fashion menyentuh dalam kehidupan sehari-hari dan mempengaruhi seseorang. Begitu pun setiap wanita ingin berpenampilan menarik, sehingga produk fashion dan wanita merupakan dua hal yang tidak bisa dipisahkan satu sama lain karena produk fashion berpengaruh terhadap penampilan fisik dan gaya hidup (Polhemus \& Procter, 2011). Seperti halnya dengan trend fashion muslim, di era modern sekarang ini fashion muslim khususnya hijab juga mengalami perkembangan setiap tahunnya dengan tidak melanggar aturan agama Islam. Kini hijab menjadi salah satu fashion yang diminati, khususnya oleh wanita muslim. 
Hal ini dikarenakan semakin tingginya tingkat kesadaran wanita muslim untuk mengenakan hijab (Sidang, 2016). Melihat fenomena tersebut para produsen berlomba-lomba berinovasi untuk membuat model hijab yang sedang diminati oleh kalangan wanita berhijab saat ini (Hadi, 2015). Hijab bukan hanya suatu kewajiban bagi wanita muslim untuk menutup aurat namun sudah menjadi kebutuhan dan penunjang penampilan wanita. Kemunculan para produsen hijab yang semakin tinggi membuat ketatnya persaingan para pelaku bisnis produsen hijab. Setiap produsen memiliki berbagai model hijab yang mempunyai keunggulan tersendiri terhadap produknya masing-masing (Fury, 2016). Berikut ini hasil penelitian merek hijab di Indonesia menurut Top Brand dapat dilihat pada tabel 1 berikut ini:

Tabel 1: Top Brand's Index Hijab 2015-2017

\begin{tabular}{|c|c|c|c|c|c|c|}
\hline \multicolumn{2}{|c|}{2015} & \multicolumn{3}{|c|}{2016} & \multicolumn{2}{|l|}{2017} \\
\hline Merek & Top & Merek & TBI & Top & Merek & Top \\
\hline Rabbani & $15.9 \%$ Тор & Zoya & $25.3 \%$ & Top & Rabbani & $16.0 \%$ Тор \\
\hline Dannis & $8.1 \%$ & Rabbani & $17.9 \%$ & Top & Zoya & $10.2 \%$ Тор \\
\hline Zoya & $8.0 \%$ & Dannis & $7.2 \%$ & & Elzatta & $5.4 \%$ \\
\hline Azka & $5.7 \%$ & Elzatta & $7.1 \%$ & & Al- Mia & $4.6 \%$ \\
\hline Almadani & $5.1 \%$ & & & & Almadani & $3.4 \%$ \\
\hline Shafira & $5.0 \%$ & & & & & \\
\hline
\end{tabular}

Sumber : (Top Brand Award)

Salah satu pangsa pasar yang dituju sebagian besar adalah para wanita muslim. Mereka berpendapat bahwa berbelanja hijab sudah menjadi bagian gaya hidup. Ketika fashion involvement sudah menjadi trend di kalangan wanita muslim, mereka akan rela membeli berbagai jenis-jenis hijab tersebut bisa berada di butik, toko atau gerai hijab lainnya dengan pelayanan, model serta kualitas hijab yang ditawarkan akan membuat pengunjung membeli produk yang diinginkan. Kecenderungan perilaku seperti ini merupakan peluang yang ditangkap para pemilik butik atau toko untuk menjual hijab yang mereka senangi. Ketika ketertarikan akan produk fashion sudah menjadi trend di kalangan muslimah dan melihat produk yang sulit dicari ditemukan, maka ia akan membeli produk tersebut meskipun ia tidak merencanakan pembelian sebelumnya, yang sering disebut dengan impulse buying (Wijaya, Hufron, \& Slamet, 2017).

Di Jombang sendiri terdapat butik-butik hijab yang menawarkan hijab bermerek salah satunya merek hijab Rabbani. Rabbani dikenal dengan tagline profesor kerudung Indonesia, dimana Rabbani merupakan salah satu perusahaan kerudung instan pertama dan terbesar di Indonesia dengan mengeluarkan produk andalan berupa krudung instan dan produk lain yang juga telah dikembangkan yaitu busana muslim baik untuk wanita maupun pria, selain itu terdapat berbagai macam aksesoris juga yang disediakan. Maka berangkat dari uraian diatas, peneliti ingin menganilisis pengaruh Shopping Lifestyle dan Fashion Involvement Terhadap Impulse Buying pada konsumen Hijab Di Butik Rabbani Jombang.

Rumusan Masalah yangdiangkat dalam penelitian ini adalah: 1) Apakah terdapat pengaruh shopping lifestyle terhadap impulse buying hijab, 2) Apakah terdapat pengaruh fashion involvement terhadap impulse buying hijab serta 3) Apakah terdapat pengaruh shopping lifestyle dan fashion involvement terhadap impulse buying hijab. Diharapkan, hasil dari penelitian ini bermanfaat bagi banyak pihak, khususnya 
perusahaan Rabbani dapat digunakan sebagai masukan atau informasi bagi pengelola perusahaan untuk mengetahui pengaruh shopping lifestyle dan fashion involvement terhadap impulse buying serta dapat digunakan sebagai bahan pertimbangan dalam menentukan langkah dan kebijakan perusahaan menghadapi perilaku konsumen.

\section{B. TINJAUAN PUSTAKA}

\section{Pengertian Shopping Lifestyle}

Menurut Levy \& Weitz (2009) shopping lifestyle adalah gaya hidup yang mengacu pada bagaimana seseorang hidup, bagaimana mereka menghabiskan waktu, uang, kegiatan pembelian yang dilakukan, sikap dan pendapat mereka tentang dunia dimana mereka tinggal. Gaya hidup seseorang dalam membelanjakan uang tersebut menjadikan sebuah status sosial, sifat dan karakteristik baru bagi seorang individu. Gaya hidup juga digunakan segmentasi pasar karena telah menyediakan pandangan kehidupan sehari-hari dari konsumen secara luas (Aziz \& V, 2015). Jika diperhatikan kebanyakan para konsumen lebih cenderung berbelanja fashion. Fashion kini sudah menjadi kebutuhan dan gaya hidup bagi hampir sebagian individu di dunia. Orang yang memiliki gaya hidup yang tinggi mereka lebih cenderung menyukai produk fashion yang bermerek dengan kualitas terbaik. Karena penampilan yang menawan, yang sejuk dipandang menjadi prioritas untuk menilai karakteristik individu.

\section{Pengertian Fashion Involvement dan Impulse Buying}

Menurut Bernard (2011) etimologi kata fashion berasal dari bahasa latin yaitu "factio" yang artinya "membuat". Fashion (mode) adalah proses sosial dimana beberapa kelompok konsumen mengunakan gaya baru. Sedangkan involvement menurut O'Cass (2004) adalah motif yang membuat seseorang tertarik atau ingin membeli suatu produk atau mengkonsumsi jasa yang ditawarkan karena dipajang maupun karena situasi yang memungkinkan. Fashion involvement adalah persepsi konsumen akan pentingnya fashion pakaian (O'cass, 2001). Pendapat ini juga sesuai pada konsep penelitian yang dikemukakan oleh Kim (2005) dalam penelitian ini fashion involvement didefinisikan sebagai ketertarikan perhatian pelanggan pada kategori fashion. Fashion involvement pada pakaian berhubungan sangat erat dengan karakteristik pribadi (yaitu wanita dan kaum muda) dan pengetahuan fashion, yang mana pada gilirannya mempengaruhi kepercayaan konsumen di dalam membuat keputusan pembelian.

Impulse buying adalah pembelian yang dilakukan di luar daftar belanja yang sudah ada tanpa direncanakan sebelumnya oleh konsumen secara spontan dan tanpa memikirkan resiko (Ratnasari, Kumadji, \& Kusumawati, 2015). Pembelian implusif bisa dikatakan suatu desakan hati secara tiba-tiba dengan penuh kekuatan, bertahan dan tidak direncanakan untuk membeli sesuatu secara langsung, tanpa banyak memperhatikan akibatnya, pendapat ini sesuai dengan konsep penelitian yang dikemukakan oleh Engel, et al (1995) dalam Japarianto \& Sugiharto, (2011) mendefinisikan impulse buying sebagai tindakan pembelian hijab yang dibuat tanpa direncanakan terlebih sebelumnya atau keputusan pembelian dilakukan pada saat berada di dalam toko atau butik hijab.

\section{Hubungan Shopping Lifestyle dengan Impulse Buying}

Berhijab bukan lagi halangan bagi muslimah yang ingin tetap tampil modis. Kini sudah banyak busana muslim yang fashionable namun tetap berpegang teguh pada aturan-aturan berpakaian yang diperintahkan dalam ajaran agama Islam. Hijab dapat diartikan kain yang menutupi kepala untuk menegaskan identitas sebagai seorang muslimah. Di era modern ini berbelanja hijab sudah menjadi gaya hidup yang 
digemari semua kalangan muslimah, untuk memenuhi gaya hidup ini mereka rela mengorbankan sesuatu demi mencapainya meskipun tidak merencanakan pembelian sebelumnya dan hal tersebut cenderung mengakibatkan impulse buying. Pendapat ini sesuai dengan penelitian Japariyanto (Japarianto \& Sugiharto, 2011), shopping lifestyle berpengaruh signifikan terhadap impulse buying. Shopping menjadi salah satu lifestyle yang paling digemari, untuk memenuhi lifestyle ini masyarakat rela mengorbankan sesuatu demi mencapainya dan hal tersebut cenderung mengakibatkan impulse buying (Prastia, 2013).

\section{Hubungan Fashion Involvement dengan Impulse Buying}

Fashion involvement adalah keterlibatan seseorang dengan suatu produk pakaian karena kebutuhan, kepentingan, ketertarikan dan nilai terhadap produk tersebut. Seo dalam penelitiannya menemukan bahwa terdapat hubungan positif antara tingkat fashion involvement dan pembelian pakaian dimana konsumen dengan fashion involvement yang tinggi lebih memungkinkan membeli pakaian (Seo, Hathcote, \& Sweaney, 2001). Konsumen dengan fashion involvement yang lebih tinggi memungkinkan terlibat dalam pembelian impulsif yang berorientasi fashion (Park, Y, \& C, 2006). Menurut Japariyanto (2011) fashion sangat terkait dengan karakteristik pribadi dan pengetahuan tentang fashion, yang pada gilirannya dipengaruhi oleh keyakinan konsumen dalam membuat keputusan pembelian. Selain itu, hubungan yang positif antara tingkat keterlibatan dan mode pembelian pakaian adalah konsumen dengan fashion involvement lebih menyukai kepada pembelian pakaian.Oleh karena itu, diasumsikan bahwa konsumen dengan fashion involvement lebih menyukai menggunakan impulse buying.

\section{Kerangka Konseptual}

Dalam penelitian ini terdapat tiga variabel yang akan diteliti, yaitu shopping lifestyle dan fashion involvement variabel independen dan impulse buying sebagai variabel dependen, kerangkan konseptual dalam penelitian ini adalah sebagai berikut:

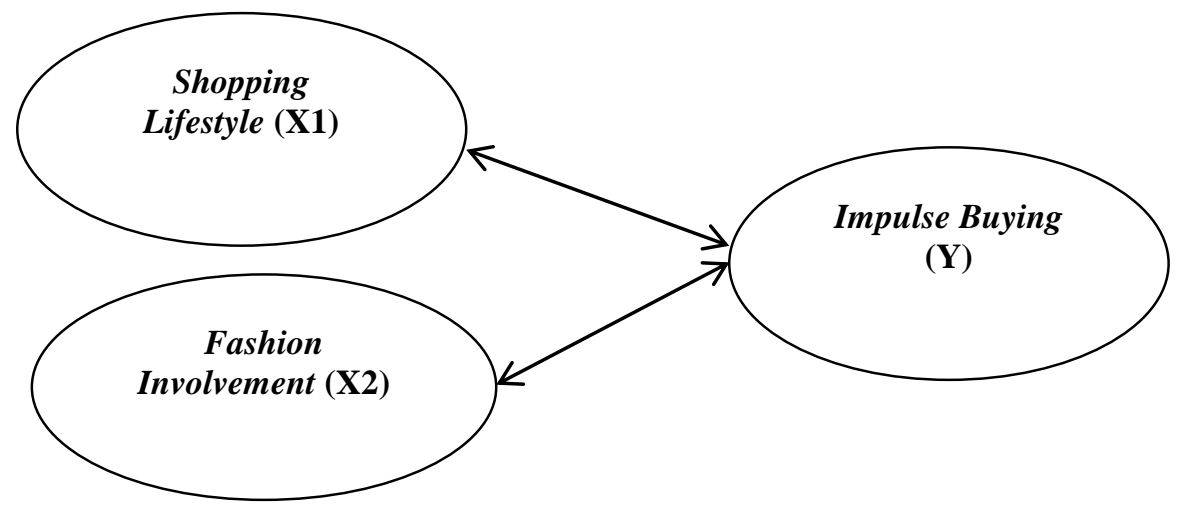

\section{Hipotesis}

Gambar 1: Kerangka konseptual

H1 : Semakin tinggi shopping lifestyle maka akan semakin kuat tingkat impulse buying di Butik Rabbani Jombang.

$\mathrm{H} 2$ : Semakin tinggi fashion involvement maka akan semakin kuat tingkat impulse buying di Butik Rabbani Jombang.

\section{METODE PENELITIAN}

\section{Desain Penelitian}


Desain dalam penelitian ini menggunakan metode penelitian kuantitatif yaitu metode penelitian yang berlandaskan pada filsafat positivisme, digunakan untuk meneliti pada populasi atau sempel tertentu (Sugiyono, 2013). Teknik pengambilan sampel dilakukan secara accidental sampling. Pengumpulan data menggunakan instrumen penelitian, analisis data bersifat kuantitatif atau statistik dengan tujuan untuk menguji hipotesis yang telah ditetapkan. Populasi dalam penelitian ini adalah pembeli di Butik Rabbani Jombang yang jumlahnya tidak diketahui. Metode pengambilan sampel adalah dengan menggunakan metode Non Probability Sampling dengan teknik Accidental Sampling yaitu dengan cara pengumpulan data yang hanya mengambil sebagian elemen populasi atau karakteristik yang ada dalam populasi.

Teknik pengumpulan data yang digunakan dalam penelitian ini adalah observasi, angket, dan dokumentasi. Skala pengukuran menggunakan skala pengukuran likert yaitu digunakan untuk mengukur sikap, pendapat dan persepsi seseorang atau sekelompok orang tentang fenomena. Skala likert yang digunakan terdapat 5 (lima) poin kriteria jawaban mulai dari sangat positif (skor lima) hingga sangat negatif (skor satu)

\section{Uji Instrumen}

Uji instrumen yang digunakan yaitu uji validitas dan uji reliabilitas. Hasil uji validatas dan uji reliabilitas mengenai disetiap indikator variabel penelitian, untuk uji validitas dapat diketahui bahwa nilai korelasi ( $\mathrm{r}$ hitung) lebih besar dari $\mathrm{r}$ tabel $(0,05)$ dan untuk melihat reliabilitasnya dapat diketahaui dari nilai cronbach'calpha lebih besar dari 0,06 sehingga dapat disimpulkan semua item pertanyaan semua indikator variabel dinyatakan valid dan reliabel dan dapat digunakan untuk penelitian selanjutnya.

\section{Teknik Analisi Data}

Tahap teknik analisa data pada penelitian ini yang pertama adalah analisa deskriptif. Analisis Deskriptif digunakan untuk menggambarkan frekuensi masingmasing item variabel dengan kategori rata-rata skor dari responden. Untuk mengetahui atau menentekan kategori jawaban responden dari masing-masing variabel tergolong tinggi, sedang atau rendah maka ditentukan skala intervalnya dengan cara sebagai berikut:

Nilai skor tertinggi- Nilai skor terendah

$$
=\frac{5-1}{5}
$$

$=0,8$

Sehingga dengan demikian dapat diketahui kategori jawaban responden masingmasing variabel yaitu :

a. Skor untuk kategori sangat tinggi : 4,2 - 5,00

b. Skor untuk kategori tinggi : 3,4 - 4,2

c. Skor untuk kategori cukup : 2,6 - 3,4

d. Skor untuk kategori rendah : 1,8 - 2,6

e. Skor untuk kategori sangat rendah : $1,00-1,8$

Selanjutnya, digunakan analisa Regresi. Analisis regresi ini digunakan untuk mengetahui pengaruh shopping lifestyle (X1) dan fashion involvement (X2) terhadap impulse buying $(\mathrm{Y})$. Analisis dalam penelitian ini menggunakan alat bantu program statistik SPSS for windows. 
Selain itu, untuk mengji hipotesis yang telah diajukan, dilakukan uji Hipotesis $(\mathrm{Uji}-\mathrm{T})$ dan Uji Determinasi yang digunakan untuk mengetahui seberapa besar pengaruh variable independen terhadap variable dependen, yang dihitung dengan rumus: $\mathrm{KD}=\mathrm{r}^{2} \mathrm{x} 100 \%$

$$
\text { Keterangan : } \begin{aligned}
\mathrm{KD} & =\text { Koefisien Determinasi } \\
\mathrm{R}^{2} & =\text { Koefisien Korelasi }
\end{aligned}
$$

\section{HASIL PENELITIAN DAN PEMBAHASAN}

Dari hasil peneitian dan pengolahan data serta melalui titahapan pengujian antara lain uji validitas, reliabilitas dan heterokedaktivitas, dinyatakan bahwa seluruh instrument layak dan bisa dilanjutkan ke tahapana analisa selanjutnya, yaitu analisis regresi berganda. Analisis ini dilakukan untuk mengetahui variabel yang ada dalam shopping lifestyle (X1) dan fashion involvement (X2) terhadap impulse buying (Y) dan membuat persamaan regresinya. Hasil perhitungan analisis berganda diolah dengan menggunakan SPSS versi 20.0 for windows. Hasil regresi dapat dilihat pada tabel 2 (dua) dibawah ini:

Tabel 2: Hasil Regresi Linier Berganda

\begin{tabular}{lcccc}
\hline Variabel & $\begin{array}{c}\text { Standardized } \\
\text { Coefficients }\end{array}$ & $\mathrm{t}$ & $\mathrm{Sig}$ & Ket \\
\hline (Constant) & 2.882 & 2.879 & .041 & Signifikan \\
Shopping Lifestyle (X1) & .461 & 5.804 & .000 & Signifikan \\
Fashion Involvement (X2) & & & & \\
$\mathrm{R}^{2} .818$ & & & & \\
$\mathrm{~F}: 217.957$ & & & & \\
\hline
\end{tabular}

sumber : data primer yang diolah, tahun 2018

Berdasarkan diatas menunjukkan bahwa nilai sig. di variabel independen lebih kecil dari $\alpha(0,05)$, maka dapat dinyatakan model regresi dapat digunakan untuk memprediksi variabel dependent.

Selanjutnya, untuk menguji hipotesis yang diajukan, dilakukan uji-t (T-Test). Hasil dari pengolahan data menggunakan alat bantu SPSS tampak pada tabel berikut:

\section{Tabel 3: Hasil Uji-T}

\begin{tabular}{cccc}
\hline Variabel & T-test & Signifikansi & Keterangan \\
\hline Shopping Lifestyle(X1) & 5.804 & 0,000 & Signifikansi \\
Fashion Involvement (X2) & 5.941 & 0,000 & Signifikansi \\
\hline
\end{tabular}

Sumber : Data Primer Yang Diolah, Tahun 2018

Berdasarkan tabel diatas hipotesis yang pertama mengenai adanya pengaruh shopping lifestyle terhadap impulse buying, hal ini dibuktikan dengan nilai signifikansi lebih kecil dari 0,05 yaitu sebesar 0,000 sehingga terdapat pengaruh antara shopping lifestyle terhadap impulse buying. Dapat disimpulkan bahwa hipotesis pertama dalam penelitian ini diterima. Hipotesis kedua adanya pengaruh fashion involvement terhadap impulse buying, hal ini dibuktikan dengan nilai signifikansi lebih kecil dari 0,05 yaitu sebesar 0,000 sehingga terdapat pengaruh antara shopping lifestyle terhadap impulse buying. Dapat disimpulkan bahwa hipotesis kedua dalam penelitian ini diterima. 
Untuk mengetahui seberapa besar pengaruh variabel bebas terhadap variabel terikat, dilakukan analisis /Uji Determinasi. Hasil Analisis/Uji Determinasi $\left(\mathrm{R}^{2}\right)$ tampak pada tabel 4 (empat) berikut:

Tabel 4: Hasil uji $\mathbf{R}^{2}$

\begin{tabular}{lllllll}
\hline Model & R & R Square & Adjusted R & $\begin{array}{l}\text { Std. Error of the } \\
\text { Estimate }\end{array}$ & $\begin{array}{l}\text { Durbin } \\
\text { Watson }\end{array}$ \\
\hline $\mathbf{1}$ & $.904^{\mathrm{a}}$ & .818 & .814 & 1.11189 & & 1.528 \\
\hline
\end{tabular}

Sumber : Data Primer Yang Diolah, Tahun 2018

Dari hasil perhitungan diperoleh nilai $\mathrm{R}$ Square sebesar 0,818 Hal ini berarti bahwa shopping lifestyle dan fashion involvement berperan baik dalam mempengaruhi konsumen untuk menentukan impulse buying di butik Rabbani yaitu sebesar $81 \%$ sedangkan sisanya sebesar $19 \%$ dipengaruhi oleh faktor lain yang tidak diteliti oleh penelitian ini.

\section{H1 = Pengaruh Shopping Lifestyle Terhadap Impulse Buying}

Shopping lifestyle memiliki pengaruh terhadap impulse buying hal ini ditunjukkan dari mayoritas respon yang disampaikan oleh responden terhadap item pertanyaan yang mendukung shopping lifestyle hijab Rabbani menunjukan respon yang positif dari konsumen hijab Rabbani terhadap impulse buying mengenai perubahan gaya hidup yang terus berkembang menjadikan konsumen ingin selalu mengikuti perkembangannya. Kebutuhan konsumen sangat berpengaruh pada gaya hidup atau lifestyle, kegiatan berbelanja menjadi salah satu tempat yang paling digemari oleh seseorang untuk memenuhi kebutuhannya.

Penelitian ini sesuai dengan penelitian yang dilakukan Putra mengenai pengaruh shopping lifestyle terhadap konsumen produk fashion (Survey pada konsumen produk fashion di Malang Town Square (MATOS) dalam penelitiannya menjelaskan bahwa shopping lifestyle memiliki pengaruh terhadap impulse buying (Putra, 2018)

\section{H2 = Pengaruh Fashion Involvement Terhadap Impulse Buying}

Fashion involvement merupakan keterlibatan konsumen terhadap suatu produk fashion yaitu pakaian (busana) yang didorong oleh kebutuhan dan ketertarikan terhadap produk tersebut atau dengan kata lain ketertarikan perhatian pelanggan pada produk fashion. . Orang yang memiliki tingkat keterlibatan dengan fashion yang tinggi mereka mempunyai lebih banyak produk fashion dan mereka memiliki pengetahuan akan setiap produk fashion yang dibeli. Hubungan yang positif antara tingkat keterlibatan dan mode pembelian pakaian adalah konsumen dengan fashion involvement lebih menyukai kepada pembelian pakaian. Oleh karena itu, diasumsikan bahwa konsumen hijab di butik Rabbani lebih menyukai impulse buying.

Hasil ini juga mendukung penelitian terdahulu yang dilakukan oleh Wijaya mengenai pengaruh fashion involvement terhadap pembelian hijab pada mahasiswi Fakultas Ekonomi Universitas Islam Malang (Wijaya, et al., 2017)

\section{E. PENUTUP}

Berdasarkan hasil penelitian dan pembahasan diatas diperoleh kesimpulan, yaitu Shopping lifestyle memiliki pengaruh positif terhadap impulse buying karena nilai signifikansi lebih kecil dari 0,05 yaitu sebesar 0,000. Selain itu Fashion involvement juga terbukti memiliki pengaruh positif terhadap impulse buying karena nilai signifikansi lebih kecil dari 0,05 yaitu sebesar 0,000. Peneliti menilai variabel shopping lifestyle dan fashion involvement mempunyai pengaruh yang positif dan sisanya dipengaruhi oleh faktor lain yang mempengaruhi terjadinya impulse buying 
hijab Rabbani faktor lain seperti usia, gender, hedonisme, matrealisme dalam membentuk impulse buying.

Berdasarkan simpulan diatas, maka disarankan kepada peneliti selanjutnya untuk menambah variabel bebas lainnya serta untuk perusahaan diharapkan menambah beragam model terbaru hijabnya karena penilaian dari responden masih dalam rentang "cukup" dan belum "tinggi", agar produknya mampu lebih menarik perhatian para pelanggan.

\section{DAFTAR PUSTAKA}

Amiri, F., Jalal, J., Mohsen, S., \& Tohid, A. (2012). "Evaluation of Effective Fashionism Involvement Factors on Impulse Buying of Costumers and Condition of Interrelation between These Factor." Journal of Basic and Applied Scientific Research, 9413-9419.

Arisandi, D., \& Pradana, M. N. R. (2018). Pengaruh Penggunaan Social Media Terhadap Brand Awareness Pada Objek Wisata Di Kota Batam. JMD: Jurnal Riset Manajemen \& Bisnis Dewantara, 1(2), 109-116.

Aziz, \& V, A. R. (2015). "Pengaruh Persepsi Risiko dan Gaya Hidup Terhadap Keputusan Pembelian Pakaian Secara Online Melalui Blackberry Messenger". eJournal Psikologi, 5.

Azwar, S. (2011). Reliabilitas dan Validitas. Yogyakarta: Pustaka Pelajar.

Cobb, C. J., \& Hoyer, D. W. (1986). "Planned versus impulse purchase behaviour". Journal of Retailing, 62, 384-409.

Deviana, N. P., \& Kt.Giantar, I. A. (2016). "Pengaruh Shopping Lifestyle dan Fashion Involvement Terhadap Impulse Buying Behaviour Masyarakat di Kota Denpasar". Manajemen Unud, 5, 5248-5249.

Engel, F. J., Roger D, B., \& Miniard, P. (2000). Perilaku Konsumen,Jilid 1,Edisi keenam. Jakarta: Binarupa Aksara.

Fury, F. R. (2016). "Keputusan Pembelian Produk Hijab (Studi Kasus Pada Toko Online MiuLan di Semarang)". Manajemen, 1.

Ghani, Usman, \& A, J. F. (2011). "An Exploratory Study of the Impulse Buying Behaviour of Urban Consumers in Peshawar". International Conference on Business ad Economics Research, 157-159.

Ghozali, I. (2006). Aplikasi Analisis Multivariate Dengan Program SPSS.Cetakan Keempat. Semarang: Badan Penerbit Universitas Diponegoro.

Ghozali, I. (2011). Aplikasi Analisis Multivariate Dengan Program SPSS. Semarang: Badan Penerbit Universitas Diponegoro.

Ghozali, I. (2012). Aplikasi Analisis Multivariate dengan Program IBM SPSS. .Yogyakarta: Universitas Diponegoro.

Hadi, R. N. (2015, June 17). Dipetik April 14, 2015, "Dari Hijab,Trend dan Aturan": https://www.kompasiana.com/rizkinurismarinihadi/hijab-trend-danaturan_555476657397733a14905529

Japariyanto, E., \& Sugiharto, S. (2011). "Pengaruh Shopping Lifestyle dan Fashion Involvement Terhadap Impulse Buying Behavior Masyarakat High Income kota Surabaya". Jurnal Manajemen Pemasaran, 6(1), 32-41.

Kim, H. (2005). "Consumer profiles of apparel product involvement and value". Journal of Fashion Marketing and Management, 9, 2. 
Kosyu, D. A. (2014). Pengaruh Hedonic Shopping Motives Terhadap Shopping Lifestyle dan Impulse Buying,. Jurnal Administrasi Bisnis (JAB).

Kotler, P. (2004). Manajemen Pemasaran, Edisi milenium. Jakarta: PT. Indeks Kelompok Gramedia.

Kotler, P., \& Amstrong. (2007). Manajemen Pemasaran Jilid Pertama. Jakarta: PT. Indeks.

Kusumandaru, A. V. (2017). "Pengaruh Price Discount, Bonus Pack, dan Instore Display Terhadap Impulse Buying Matahari". Jurnal Ilmu dan Riset Manajemen, 6, 5.

Levy, M., \& Weitz, A. B. (2009). Retailing Manajemen.7Ed. New York: Mc Graw Hill.

Ma'ruf, H. (2006). Pemasaran Ritel. Jakarta: PT Gramedia Pustaka Utama.

Mowen, J., \& Minor. (2002). Prilaku Konsumen jilid 2. Jakarta: Erlangga.

Nawari. (2010). Analisis Regresi dengan MS Excel 2007 dan SPSS. Jakarta: PT Elex Media Komputindo.

Nugroho, S. J. (2003). Perspektif Kontemporer pada Motif, Tujuan, dan Keinginan Konsumen Edisi Revisi,Cetakan Kelima. Dalam Perilaku Konsumen (hal. 9). Jakarta: Kencana Prenada Media Group.

O'Cass, A. (2004). "Fashion clothing consumption antecedents and consequences of fashion clothing involvement". Journal of Marketing, 38, 869-882.

Park, Jihye, \& Lennon, S. J. (2006). "Psychological and Environmental Antecedents of Impulse Buying Tendency in The Multichannel Shopping Context". Journal of Consumer Marketing, 23(2), 58.

Park, J. E., Y, K. E., \& C, F. J. (2006). "A structural model of fashion-oriented impulse buying behaviour". Journal of fashion marketing and management, 10, 433-446.

Peter, Paul, J., \& Olson, J. C. (2002). Consumer Behavior and Marketing Strategy 6th Edition. New York: Mc Graw Hill.

"Pengertian Hipotesis". (2013, Juni). Dipetik April 28, 2018, dari http://www.temukanpengertian.com/2013/06/pengertian-hipotesis.html

Prastia, E. F. (2013). "Pengaruh Shopping Lifestyle, Fashion Involvement dan Hedonic Shopping Value Terhadap Impulse Buying Behaviour Pelanggan Toko Elizabeth Surabaya". Jurnal Manajemen \& Kewirausahaan, 7.

Purnama, Y. (2015, October 17). "Makna Hijab, Khimar dan Jilbab". Diambil kembali dari https://muslim.or.id/26725-makna-hijab-khimar-dan-jilbab.html

Putra, F. K. (2018). Pengaruh Shopping Lifestyle, Usia dan Gender Terhadap Impulse Buying Produk Fashion (Survey Pada Konsumen Produk Fashion di Malang Town Square (MATOS)). 9.

Rabbani News. (2017, Juli 25). Dipetik Juni 27, 2018, "Dari Fashion News dan Trends Rabbani Raih Penghargaan Indonesia Original Brand": https://rabbani.co.id/page/artikel-Rabbani-Raih-Penghargaan-IndonesiaOriginal-Brand-2017-6-48.html

Ratnasari, A. V., Kumadji, S., \& Kusumawati, A. (2015, Januari 1). "Pengaruh Store Atmosphere Terhadap Hedonic Shopping Value Dan Impulse Buying". Jurnal Administrasi Bisnis (JAB), 1, 3.

Riadi, M. (2018, April 27). "Pengertian, Jenis, Indikator dan Faktor yang Mempengaruhi Gaya Hidup". Dipetik Maret 3, 2018, dari 
https://www.kajianpustaka.com/2018/03/pengertian-jenis-indikator-dan-faktoryang-mempengaruhi-gaya-hidup.html

Rohim, A., \& Arvianto, S. (2017). Pengaruh Customer Perceived Value Terhadap Word Of Mouth Dengan Customer Loyalty Sebagai Variabel Mediasi (Study Kasus Di CV Putra Putri). Eksis: Jurnal Riset Ekonomi dan Bisnis, 12(1).

Rook, D., \& Fisher, R. (1995). Normative Influences on Impulsive Buying Behavior. Oxford University: Press, 22.

Saefuddin, A. (2010). Statistik Dasar. Jakarta: PT Gramedia Widiasarana Indonesia.

Santoso, S. (2000). Buku Latihan SPSS Statistik Parametrik. Jakarta: PT Flex Media Komputindo.

Santoso, S. (2003). Mengatasi Berbagai Masalah Statistik dengan SPSS versi 11.5. Jakarta: PT. Elex Media Komputindo.

Seo, J., Hathcote, M. J., \& Sweaney, L. A. (2001). "Casualwear shopping behavior of college menin Georgia". Journal of Fashion Marketing and Management, 5, 208-222.

Sidang, N. K. (2016). "Fenomena trend fashion jilbab dalam keputusan pembelian jilbab". jurnal ekonomi islam, 1-2.

Sugiyono. (2013). Metode Penelitian Bisnis. Bandung: Alfabeta.

Sumarwan, U. (2011). Perilaku Konsumen Teori dan Penerapannya dalam Pemaasaran. Bogor: Ghalia Indonesia.

Sunarto, K. (2000). Pengantar sosiologi. Edisi kedua. Depok: Fakultas Ekonomi Universitas Indonesia.

Tendai, M., \& Chipunza, C. (2009). "In-store environment and impulsive buying". African Journal of Marketing Management, 1, 102-108.

Tirmizi, Ali, M., Shaif, M. I., \& Saif, M. I. (2009). "An empirical Study of consumer impulse buying behaviour in local markets". European journal of scientific research., 28, 522-532.

Top Brand Award. (t.thn.). "Top Brand Award". Dipetik April 13, 2018, dari http://www.topbrand-award.com/

Tribun Bisnis. (2014, Mei 20). Dipetik Juni 1, 2018, dari "Fatin Ikut Dongkrak Penjualan Kerudung Rabbani Hingga Capai Rp 500 Miliar": http://www.tribunnews.com/bisnis/2014/05/20/fatin-ikut-dongkrak-penjualankerudung-rabbani-hingga-capai-rp-500-miliar

Utami, O., \& Rastini, N. (2015). "Pengaruh variabel demografi, kualitas layanan, atmosfer toko pada Impulse Buying Di Hypermart Mall". E-Jurnal Manajemen Unud, 4(5), 1229-1237.

Utami, W. C. (2010). Manajemen Ritel: Strategi dan Implementasi Ritel Modern. Jakarta: Salemba Empat.

Utami, W. C. (2012). Manajemen Ritel. Jakarta: Salemba Empat.

Wijaya, A. M., Hufron, M., \& Slamet, A. R. (2017). "Pengaruh Shopping Lifestyle dan Fashion Involvement (Studi Kasus Pembelian Hijab Pada Mahasiswi Fakultas Ekonomi Universitas Islam Malang)". Riset Manajemen, 3. 